DOI 10.37882/2223-2982.2020.11-2.19

\title{
МЕТОДОЛОГИЧЕСКИЕ ПОДХОДЫ В ФОРМИРОВАНИИ ИНФОРМАЦИОННОЙ ГРАМОТНОСТИ ДЕТЕЙ ДОШКОЛЬНОГО ВОЗРАСТА
}

\section{METHODOLOGICAL APPROACHES IN THE FORMATION OF INFORMATION LITERACY IN PRESCHOOL CHILDREN}

Zhang Shu

Summary: The 21st century is an information society, and everyone, without exception, is involved in the information wave. Information technology is playing an increasingly important role. They change people's lives and methods of production, and they also cause a number of changes in people's mental performance, such as thinking, emotions, moral concepts and psychological needs. These changes encourage thinking about the formation of information literacy in preschoolers in modern society. As a philosophical issue in scientific research, the methodological approach plays a fundamental role. We believe that in the process of forming information literacy in preschool children, three methodological approaches should be adopted: a person-centered approach, an anthropological approach and a participatory approach.

Keywords: information literacy, preschool children, methodological approach, personality-oriented approach, anthropological approach and participatory approach.

\section{Введение}

$\mathrm{B}$ о второй половине 20 века человечество начало переход от индустриального общества к информационному. Информационное общество относится к «новому типу общества, основанному на компьютерных сетевых технологиях, информационных ресурсах в качестве основных ресурсов развития, индустрии информационных услуг в качестве базовых социальных отраслей, а цифровизация и создание сетей в качестве основных методов социального взаимодействия». В этом случае информационные технологии играют все более важную роль. Они изменяют жизнь людей и методы производства, а также вызывают ряд изменений в умственной деятельности людей, таких как мышление, эмоции, моральные концепции и психологические потребности. Эти изменения побуждают задуматься о формировании информационной грамотности дошкольников в современном обществе. Как философский вопрос научной исследовании методологический подход играет фундаментальную роль.

\author{
Чжан Шу \\ аспирант, Южно-Уральский государственный \\ гуманитарно-педагогический университет, Челябинск \\ zhangshu2019@yandex.ru
}

Аннотация: XXI век - это информационное общество, и все без исключения вовлечены в информационную волну. Информационные технологии играют все более важную роль. Они меняют жизнь людей и методы производства, а также вызывают ряд изменений в умственной деятельности людей, таких как мышление, эмоции, моральные концепции и психологические потребности. Эти изменения побуждают задуматься о формировании информационной грамотности дошкольников в современном обществе. Как философский вопрос научной исследовании методологический подход играет фундаментальную роль. Мы считаем, что в процессе формировании информационной грамотности детей дошкольного возраста следует принять три методологического подхода: личностно-ориентированный подход, антропологический подход и партисипативный подход.

Ключевые слова: информационная грамотность, дети дошкольного возраста, методологический подход, личностно-ориентированный подход, антропологический подход и партисипативный подход.

\section{Смысл и значение методологического по $х$ хода}

Конкретно-научная методология каждой науки и обслуживаемой ею практики раскрывается через специфические относительно самостоятельные подходы[1].

Теоретико-методологическое основание формировании информационной грамотности детей дошкольного возраста в исследовательской деятельности определяет комплекс стратегических направлений исследования и совокупность соответствующих методологических подходов. Как А.М. Новиков и Д.А. Новиков пишут, что методологический подход к организации научной деятельности может рассматриваться как некоторый исходный принцип, исходная позиция, основное положение или убеждение, например: функциональный подход, системный подход, синергетический подход и т.п.[2]. Например, в «знаниевом» подходе роль педагога - лидер, его функции в основном - преподаватель-лектор и преподаватель семинарских, а в компетентностном подходе роль педагога - организатор и систематизатор процесса обучения; его функции - тьютор коуч (креативный настав- 
ник, фасилитатор (помощник) при рейтинговой системе оценивания[3].

В науке представлено многообразие подходов, которые при взаимосвязи с другими могут решать проблемы построения и внедрения концепции формировании информационной грамотности детей дошкольного возраста в исследовательской деятельности. Поскольку каждый методологический подход в образовании обладает своим набором действенных принципов, то необходимо комплексно использовать совокупности методологических подходов.

В современной философии понятие методологического подхода рассматривается по-разному различными учеными. Н. Стефанов определяет методологический подход как «совокупность (систему) принципов, которые определяют общую цель и стратегию соответствующей деятельности»[4].Исследовательский подход определяется как исходный принцип, исходная позиция исследователя[5]. И.В. Блауберг и Э.Г. Юдин рассматривают методологический подход как «принципиальную методологическую ориентацию исследования, как точку зрения, с которой рассматривается объект изучения (способ определения объекта)» [6]. В исследовании формировании информационной грамотности детей дошкольного возраста в исследовательской деятельности мы соглашаемся с Е.Ю. Никитиной, Л.В. Трубайчук и др. о том, что подход - это основа исследовательского процесса, особая форма познавательной и практической деятельности, рассмотрение педагогических явлений под определенным углом зрения ,стратегия исследования изучаемого процесса, базовая ценностная ориентация, определяющая позицию педагога[1][7].

\section{Методологический подхо в формировании

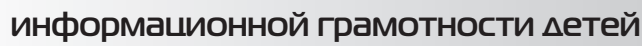 Аошкольного возраста}

Таким образом, мы пришли к выводу, что формирование информационной грамотности детей дошкольного возраста в исследовательской деятельности должно основываться на использовании личностно ориентированного подхода как исходном принципе, и основном положении [8]; антропологического подхода как философской основы для согласования информационных технологий с характеристиками дошкольников; партисипативного подхода как совокупности приемов, способов, на поиске результативных организационно-педагогических условий, которые позволят, раскрывая ведущую роль учителей, максимизировать инициативу и субъективность учащихся, тем самым поднимать информационную грамотность учащихся на качественно новый уровень[8].

\section{^ичностно-ориентированный подхоА}

Личностно-ориентированный подход в педагогике относится к гуманистическому направлению. Гуманистическая психология, предложенная К. Рождерс, является основным направлением в современной психологии. Она признаёт главным предметом личность человека как уникальную целостную систему, которая способна к самоактуализации. 21 век - информационное общество, и также , 2020-е годы для каждого человека- это совершенно новый этап, отличный от любой предыдущей эпохи, его динамическими проблемами и неопределенностями. Эти характеристики современного общества требуют от нас внимания к развитию конкурент способности личности, пластичности, гибкости, способности быстро адаптироваться и адекватно реагировать на малейшие изменения во всех сферах жизнедеятельности[9], особенно в использовании IT- технологий. Это одна из важных задач, стоящих перед дошкольным образованием. На основании данного высказывания можно сделать вывод о необходимости реализации личностно ориентированного подхода в процессе формировании информационной грамотности детей дошкольного возраста в исследовательской деятельности.

Из отечественных ученых которые исследовали именно этому направлению необходимо назвать Е.В. Бондаревской, М.М. Рубинштейна, В.М. Бехтерева, Л.С. Выготского, П.П. Блонского, А.Ф. Лазурского, Ю.И. Турчанинового, Э.Н. Гусинского, В.В. Серикового, О.С. Газман, И.С. Якиманского из зарубежных - М. Монтессори, М. Макмиллана, О. Декроли , К. Рождерс и других[1,12].

Личностно-ориентированный подход - это методологическая ориентация в педагогической деятельности, позволяющая посредством на систему взаимосвязанных понятий, идей и способов действий обеспечить и поддержать процессы самопознания, самостроительства и самореализации личности ребенка, развитие его неповторимой индивидуальности[10]. В педагогике личность является целью, субъектом, результатом и главным критерием эффективности педагогического процесса[11].

Личностно-ориентированный подход подтверждает энтузиазм, инициативу и творческий потенциал человека в обучении. Он предполагает организацию деятельности, в которой ребёнок выступает как лицо активное и инициативное, индивидуальное и своеобразное; все конкретные дела являются замыслом детей, их волей; развитие личности в образовательном процессе идёт через постоянное обогащение, преобразование, рост и качественное изменение субъектного опыта и связанных с ним личностных смыслов[1].

Древний мыслитель и философ Китая Конфуций 2500 
лет назад выдвинул принцип «вести учение сообразно индивидуальным способностям», который заключается в применении различных образовательных методов и содержания в зависимости от способностей, личности, интересов и других конкретных условий учащихся.

Актуальность использовании личностно ориентированного подхода в формировании информационной грамотности детей дошкольного возраста в исследовательской деятельности определяют характеристика современного общества и особенностей возрастных, индивидуальных психологических и физиологических детей дошкольного возраста. 1) Разделение труда в современном обществе становится все более и более тонким, а конкуренция в науке и технике усиливается: независимо от того, в какой стране мы должны развивать инновационные таланты с независимыми личностями и полными личностями. 2) «Федеральный государственный стандарт дошкольного образования» отметит, что «должно обеспечивать развитие личности, мотивации и способностей детей в различных видах деятельности» , и также рассматривает развития личности детей дошкольного возраста в качестве одного из основных принципов реализации программы. Во всем тексте документа «личность» упоминается восемь раз. 3) Нынешним детей дошкольного возраста свойственны независимость и раскрепощенность, прагматичность мыслей и действий, а это, в свою очередь, обуславливает использование педагогами новых форм и стилей общения в процессе взаимодействия педагог - учащийся, построение личностно-ориентированных методов обучения и воспитания.

Итак, личностно-ориентированный подход играет важную роль в этом исследовании формировании информационной грамотности детей дошкольного возраста в исследовательской деятельности. «Информационная грамотность - базовое право человека в цифровом мире» [13]. Дошкольник - это постоянно развивающаяся личность, и в процессе индивидуального развития открываются неограниченные возможности.

\section{Антропологический по $х х о \Delta$}

Антропологический подход возник в конце 60-ых начале 70-ых годов 20-го столетия[19]. Его впервые разработал и обосновал К.Д. Ушинский. В его понимании он означал системное использование данных всех наук о человеке как предмете воспитания и их учет при построении и осуществлении педагогического процесса[23].

Чтобы понять, что есть «антропологический подход», посмотрим термин «антропология». Антропология (от

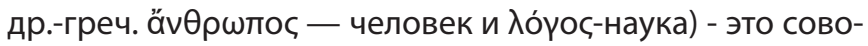
купность научных дисциплин, занимающихся изучением человека, его происхождения, развития, существования в природной (естественной) и культурной (искусствен- ной) средах[20][21]. Возникновение термина «антропология» восходит к античной философии. Древнегреческий философ Аристотель первым употребил его для обозначения области знания, изучающей преимущественно духовную сторону человеческой природы[22]. Антропология проявляет внимание о технологиях с самого начала. В 1978 году немецкий философ Ганс Закс выдвинул концепцию «антропология технологии»[24].

Так же, многие ученые посвящают себя совмещению «антропологии» и «педагогики». Н.И. Пирогов впервые употребил термин «педагогическая антропология» в своей знаменитой статье «Вопросы жизни», а К.Д. Ушинский уточнил, наполнил конкретным содержанием в специальном многотомном труде «Человек как предмет воспитания. Опыт педагогической антропологии». В.И. Максакова в учебном пособии раскрыто содержание курса «Педагогическая антропология», интегрирующего представления о ребенке, содержащиеся в различных науках, искусстве, обыденном педагогическом сознании[21]. Под педагогической антропологии учащийся считается личностью с индивидуальными качествами, являющуюся целостной структурой и развитой системой.

С точки зрения антропологии технологии, в том числе информационные технологии, являются частью человеческой культуры. В процессе формировании информационной грамотности детей дошкольного образовании информационные технологии не изолированы, а должны быть связаны с возрастными характеристиками детей дошкольного образовании, особенностями развития, культурными особенностями и их окружающей среды.

Антропология - это наука о человеке, предает большое значение биологии и культуре человека. Как и всё другое живое, человек - это живая личность, которая может воспринимать, отражать и независимо реагировать на все стимулы. Без сомнения дети дошкольного возраста - существо динамичное развивающееся их органы системы мозга и мышления постоянно меняются.

Информационные технологии в современном обществе проникли во все аспекты жизни людей. С одной стороны, это принёс большое удобство в нашу учебу и жизнь, с другой стороны, также практически снизило физическую активность людей. Для детей дошкольного возраста, как цифровые аборигены, это особенно актуально. Дети дошкольного возраста сосредотачиваются на цифровое оборудование, их физическая активность, восприятие органов тела и коммуникативная деятельность активность значительно снижены. Они сидят неподвижно, как машины. Это явление пагубно сказывается на развитии детей и противоречит характеристикам динамичное детей. Чтобы разрешить это противоречие 
в формировании информационной грамотности детей дошкольного возраста, необходимо использование антропологического подход, который позволяет рассматривать человека как существо, воплощающееся в гармонии социального и биологического бытия.

Итак, антропологический подход играет важную роль в исследовании формировании информационной грамотности детей дошкольного возраста в исследовательской деятельности, а именно:

1. Антропологический подход наделяет детей дошкольного возраста миссией быть высшей мерой вещей, технологий, отношений в формирования информационной грамотности в исследовательской деятельности

2. В процессе формирования информационной грамотности детей дошкольного возраста в исследовательской деятельности детей дошкольного образования следует рассматривать как личностям с биологическими и культурными особенностями, уделять внимание и развивать их зрение, слух, осязание, моторику и коммуникативные навыки.

3. Антропологический аспект позволяет детям дошкольного возраста научиться наблюдать, разрабатывать и оценивать информационные технологии, так что дети дошкольного возраста могут стать активными и фактическими участниками, а не «вассалами» цифровых устройств.

\section{Партисипативный подхо $\Delta$}

Партисипативный подход рассматривается нами как процесс и результат партисипативного обучения. Понятие «партисипативность» оформилось в кадровом менеджменте первоначально как одна из теорий мотивирования персонала. В дальнейшем данная теория развилась в концепцию партисипативного управления[14].

Значительный вклад в разработку основ подхода внесены отечест-венные ученые как Е.Ю. Никитиной, Е.А. Казаева, О.Ю. Афанасьевой, И.В. Касьяновой, И.А. Кравченко, М.В. Смирновой, И.А. Баткчева, И.Е. Ворожейкин, Д.К. Захаров, Е.А. Митродинова, В.М. Свистунов и др., зарубежные как Дункан Дж. У., Деминг, Уильям Эдвардс, Б. Карлофф и др.[18].

Партисипативный подход был впервые разработан Е.Ю. Никитиной в теории и методике профессионального образования применительно к подготовке будущего учителя в области управления дифференциацией образования[15].

Исследователи давно обнаружили, что «люди предпочитают делать те вещи, относительно которых их собственные решения играли существенную роль. Они производят больше, достигают цели более эффективно и испытывают большее удовлетворение от работы или групповых решений, чем когда они подчиняются приказу свыше»[16].

Как руководители образовательной деятельности, педагоги должны осознать, что «И если хоть кто-нибудь оспаривает ходячее мнение, возблагодарим его за это, выслушаем и порадуемся, что он делает для нас то, что иначе пришлось бы с огромным трудом делать самим»[17].

Процесс формирования информационной грамотности детей дошкольного возраста носит длительную, исследовательскую и комплексную специфику, что определяет необходимость использования партисипативный подход в формировании информационной грамотности дошкольного образования в исследовательской деятельности.

Мы применяем партисипативный подход для формирования информационной грамотности дошкольного возраста, что имеет следующее значение:

1. Стимулировать интерес детей дошкольного возраста к информационным технологиям. В партисипативном обучении педагоги и дошкольники становятся равными собеседниками, и дети дошкольного возраста могут задавать любые интересующие их вопросы в области информационных технологий;

2. Повысить способность дошкольников использовать информационные технологии. В партисипативного обучении благодаря личному управлению цифровым оборудованием, поиску информации и проверке гипотез способность детей дошкольного возраста к опросу значительно улучшится;

3. Помочь воспитать у детей дошкольного возраста способность к сотрудничеству. Партисипативный подход требуют специальные организационные форм и структуры. В процессе формирования информационной грамотности детей дошкольного возраста в деятельности создаются несколько групп для сбора информации и поиска ответов на вопросы. Это значительно улучшит способность дошкольников к сотрудничеству.

Реализация партисипативного подхода требует определенных принципов для обеспечения, отсутствие этих принципов эффективность партисипативного обучении пропадает. Партисипативное обучение требуется для: 1) добровольного характера участия сотрудников в малых группах; 2) постоянной помощи и поддержки руководителем учебной деятельности, необходимой для обсуждения информации; 3) принимания любых идей и предложений с терпением; 4) оценки, обратной связи по любым идеям и предложениям обучающихся; 5) Любые достижения обучающихся должны быть записаны, и об- 
учающийся должен знать, какие из их достижений ценны[14].

Осуществляя партисипативный подход в процессе формирования информационной грамотности детей дошкольного возраста в исследовательской деятельности, педагог должен исходить их того, что:

1. каждый дошкольник - уникальная личность, поэтому стандартные теоретико-методологические стратегии к его подготовке не всегда применимы; они должны быть сформулированы применительно к конкретному человеку и данной ситуации;

2. взаимодополнительность способностей использования информацию детей дошкольного возраста в учебной группе и общность основных ценностных установок обеспечивают полноценное использование их индивидуальных возможностей и особенностей при достижении общих целей в процессе формирования информационной грамотности в исследовательской деятельности;

3. необходимо наличие сознательной информационной коммуникации, выдающиеся цели должны формулироваться таким образом, чтобы энергия группы детей дошкольного возраста могла быть конструктивно направлена на их достижение; 4) активное участие всех детей дошкольного возраста в анализе проблем и перспектив в процессе формирования информационной грамотности, планировании совместных действий, оценке полученных достижений.

\section{ЗакАючение}

Подводя итог вышесказанному, подчеркиваем ключевые позиции личностно-ориентированного, антропологического и партисипативного подходов, опора на которые позволила нам осуществить эффективный процесс формировании информационной грамотности детей дошкольного возраста.

\section{ЛИТЕРАТУРА}

1. Трубайчук, Л.В. Методология и методика психолого-педагогических исследований; ИиуМ «Образование»: Челябинск, Россия, 2008. pp15-20.

2. Новиков, А.М., Новиков, Д.А. Методология научного исследования. Либроком: Москва, Россия, 2014. pp. 109-119.

3. Кудаков, 0.Р. Структурные уровни методологического подхода в образовании. Ј. Вестник Казанского государственного энергетического университета.2010. 3 (6). 127-130.

4. https://www.elibrary.ru/item.asp?id=15624394

5. Стефанов Н. Мультипликационный подход и эффективность. Прогресс: Москва, Россия, 1976.р 27.

6. Анисимов, В.В., Грохольская О.Г., Никандров, Н.Д. Общие основы педагогики: Учеб. для вузов. Просвещение: Москва, Россия, 2006. рр301-302 .

7. Блауберг, И.В., Юдин Э.Г. Становление и сущность системного подхода. Наука: Москва, Россия, 1973.pp74-75.

8. Никитина, Е.Ю. Педагогическое управление коммуникативным образованием студентов вузов [Текст]: перспективные подходы. МАНПО: Москва, Россия, 2006. pp.101-103.

9. Ипполитова, Н.В. Сущность и функции методологического подхода в педагогическом исследовании. J. Преподаватель XXI век. 2011.3.57-60. https:// cyberleninka.ru/article/n/suschnost-i-funktsii-metodologicheskogo-podhoda-v-pedagogicheskom-issledovanii

10. Воскрекасенко, 0.А. Личностно-ориентированный подход к развитию адаптационных способностей будущих педагогов в высшей школе. Ј. Известия Пензенского государственного педагогического университета им. В.Г. Белинского. 2011.24.593-597. https://cyberleninka.ru/article/n/lichnostnoorientirovannyy-podhod-k-razvitiyu-adaptatsionnyh-sposobnostey-buduschih-pedagogov-v-vysshey-shkole

11. Степанова, Е.Н. Личностно-ориентированный подход в работе педагога: разработка и использование.ТЦ Сфера: Москва ,Россия, 2004.pp.99-101.

12. Никитина, Е.Ю. Коммуникативная подготовка младших школьников в языковом образовании .Ј. Вестник челябинского государственного педагогического университета .2013.1.79-90. https://www.elibrary.ru/item.asp?id=19624227

13. Ахвердиев, К.Н. Основные методологические подходы в педагогике .J. Молодой ученый. 2010. 6. 308-310. https://moluch.ru/archive/17/1674/

14. Педагогические аспекты формирования медийной и информационной грамотности, Available online: https://iite.unesco.org/pics/publications/ru/ files/3214708.pdf (accessed on 1 August 2020).

15. Казаева, Е.А. Роль партисипативности системе высшего образования. J. Педагогическое образование в России.2014.1.25-30. https://www.elibrary.ru/item. asp?id=21129091

16. Орлов, А.Б. Феномены эмпатии и конгруэнтности. Ј. Вопросы психологии. 1993. 6.68 - 73. https://www.elibrary.ru/item.asp?id=22735556

17. Дункан, Дж.У. Основополагающие идеи в менеджменте. Уроки основоположников менеджмента и управленческой практики: пер. с англ. Дело: Москва, Россия, 1996. pр.109-110.

18. Джон Стюарт Милль: «о Свободе». Available online: https://old.inliberty.ru/library/491-0-svobode (accessed on 1 August 2020).

19. Шкитина, Н.С., Касаткина, Н.С. Педагогические модели партисипативной подготовки студентов педагогических вузов. Ј. Вестник Южно-уральского государственного гуманитарно-педагогического университета.2019.2 194-209 https://www.elibrary.ru/item.asp?id=40090441

20. Максакова, В.И. Педагогическая антропологи, 2th ed.; Издательский центр «Академия»:Москава,Россия,2004.pp.102-104.

21. Константинова, Ф.В. Философская энциклопедия, 2th ed.; Советская энциклопедия: Москва, Россия, 1960.pp201-202. 
22. Воронцова Л.П., Белик А.А. Культурология. ХХ век. Энциклопедия; Университетская книга: Санкт-Петербур,Россия, 1998. pp 223-224.

23. Антропология - статья из Большой советской энциклопедии. Рогинский Я.Я.. .Available online: http://bse.sci-lib.com/article063892.html (accessed on 1 August 2020).

24. Сластенин В.А. и др. Педагогика: Учеб. пособие для студ. высш. пед. учеб. заведений. Издательский центр «Академия»: Москва, Россия, 2002. рр 234-236. 25. Hans Sachsse. Anthropology of technology. A contribution to the position of man in the world. Vieweg: Braunschweig ,German ,1978.pp 304-305.

(c) Чжан Шу (zhangshu2019@yandex.ru).

Журнал «Современная наука: актуальные проблемы теории и практики»

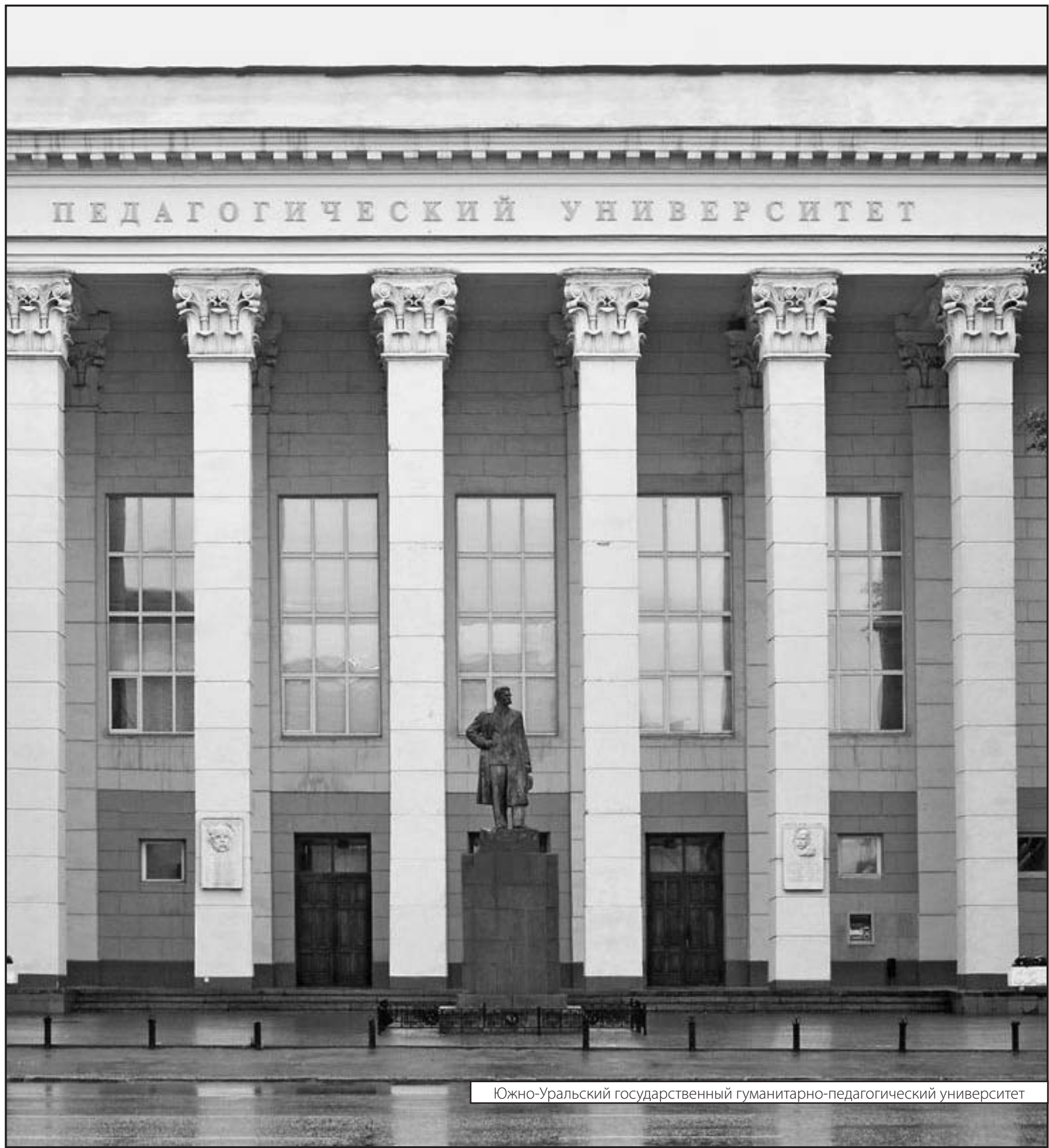

